\title{
Estado do Conhecimento sobre Sustentabilidade, Educação Ambiental e Agrícola no Ensino de Química no Ensino Médio
}

\author{
State of Knowledge on Sustainability, Environmental and Agricultural \\ Education no Chemistry Education no Medium Education
}
Estado de los conocimientos sobre sostenibilidad, educación ambiental y agrícola en la enseñanza de la química en el bachillerato

\author{
Ilda De Franceschi Fellipetto (ilda.fellipetto@ sou.unijui.edu.br) \\ Universidade Regional do Noroeste do Estado do Rio Grande do Sul -UNIJUI. \\ Otavio Aloisio Maldaner (otaviomaldaner@gmail.com) \\ Universidade Regional do Noroeste do Estado do Rio Grande do Sul -UNIJUI. \\ Maria Cristina Pansera de Araújo ( pansera@unijui.edu.br) \\ Universidade Regional do Noroeste do Estado do Rio Grande do Sul -UNIJUI
}

Resumo: O presente estudo pesquisou o estado do conhecimento da Sustentabilidade, Educação Ambiental (EA) e Agrícola no ensino de Química no Ensino Médio a partir de uma busca bibliográfica realizada no Catálogo de Teses e Dissertações da Coordenação de Aperfeiçoamento de Pessoal de Nível Superior (CAPES) no período de 2015 a 2019. Foram localizadas algumas dissertações e Teses relacionadas a temática que reiteraram a pertinência do estudo realizado, bem como, de discussões mais amplas no meio acadêmico e científico. De acordo com o estudo, foi possível destacar que apesar da EA e a Sustentabilidade estarem presentes em inúmeros documentos que norteiam as diretrizes curriculares para o Ensino Médio, ainda são incipientes os estudos realizados nessa etapa da Educação, especialmente, na disciplina em análise.

Palavras-chave: Transversalidade; Química; Educação; Meio Ambiente; Impactos Agrícolas.

Abstract: The present study investigated the state of knowledge of Sustainability, Environmental Education (EA) and Agricultural in the teaching of Chemistry in High School from a bibliographic search carried out in the Catalog of Theses and Dissertations of the Coordination for the Improvement of Higher Education Personnel (CAPES) in the period from 2015 to 2019. Some dissertations and Theses related to the

Recebido em: $18 / 11 / 2020$

Aceite em: $27 / 07 / 2021$ 
theme were found that reiterated the pertinence of the study carried out, as well as of broader discussions in the academic and scientific environment. According to the study, it was possible to highlight that despite the EA and Sustainability are present in numerous documents that guide the curricular guidelines for High School, the studies carried out in this stage of Education are still incipient, especially in the discipline under analysis.

Keywords: Transversality; Chemistry; Education; Environment; Agricultural Impacts.

Resumen: El presente estudio investigó el estado del conocimiento de la Sustentabilidad, Educación Ambiental (EA) y Agrícola en la docencia de la Química en el Bachillerato a partir de una búsqueda bibliográfica realizada en el Catálogo de Tesis y Disertaciones de la Coordinación para la Perfeccionamiento del Personal de Educación Superior (CAPES) en el período de 2015 a 2019. Se encontraron algunas disertaciones y tesis relacionadas con el tema, las cuales reiteraron la relevancia del estudio realizado, así como de discusiones más amplias en el ámbito académico y científico. Según el estudio, se pudo resaltar que a pesar de que la EA y la Sostenibilidad están presentes en numerosos documentos que orientan los lineamientos curriculares para Bachillerato, los estudios realizados en esta etapa de la Educación son aún incipientes, especialmente en la disciplina bajo análisis.

Palabras-clave: Transversalidad; Química; Educación; Medio ambiente; Impactos agrícolas.

\section{INTRODUÇÃO}

De acordo com Paiva et al (2016), no cenário atual da Educação Escolar tem-se discutido que os procedimentos de ensino são tão importantes quanto os próprios conteúdos de aprendizagem. Desta forma, técnicas de ensino passam a fazer parte do escopo de teóricos, não só da área da Educação, mas de toda a comunidade intelectual que busca identificar suas deficiências e propor novas metodologias de ensinoaprendizagem, bem como a aplicabilidade dos conteúdos relacionados a temas transversais em todas as modalidades e disciplinas que compõem o currículo escolar.

Outros estudiosos (MALDANER; ZANON; AUTH, 2007) dos currículos escolares propõem a necessidade de compreender quais conhecimentos sistematizados das diferentes disciplinas curriculares têm maior potencial de fazer sentido no mundo da vida dos estudantes (VIGOTSKI, 2009), permitindo que se constituam na cultura científica com mais qualidade e possam participar com responsabilidade em sua

Recebido em: $18 / 11 / 2020$

Aceite em: $27 / 07 / 2021$ 
recriação no enfrentamento dos grandes problemas que afligem e que ainda afligirão a sociedade em seu tempo.

Como exemplo dessas problemáticas, podemos citar a questão ambiental. Segundo os teóricos da abordagem histórico cultural de raiz vigotskiana, como Davidov e Zinchenko (1994), o ser humano é um produto original da natureza, mas ele é especial porque foi se tornando capaz de adequar determinados limites naturais às suas necessidades de sobrevivência. Desta forma o ser humano aprendeu a agir sobre a natureza, modificando-a e modificando-se em uma nova linha evolutiva, a linha cultural. Entende-se como cultura tudo aquilo que os seres humanos criaram ao longo de sua vida e que pode ser deixado como herança a ser ensinada e aprendida na sucessão das gerações (SANTOS; AULER, 2011).

Esse processo, porém, criou, entre outros grandes problemas sociais contemporâneos, a degradação ambiental, que está se agravando ano a ano, como as mudanças climáticas globais, poluição dos diferentes ambientes terrestres, aquáticos e atmosférico de tal maneira que já afeta a qualidade de vida de todos (CORRÊA et al, 2019). Por causa disso, muitos grupos sociais passam a negar a Ciência como um bem necessário às pessoas e comunidades, esquecendo que tal processo de degradação é necessário Ciência e Tecnologia favorável para permitir produzir soluções para problemas causados por práticas exploratórias da natureza incompatíveis na preservação da vida no Planeta como um todo (SANTOS; SCHNETZLER, 2015).

Nesse contexto enquadra-se a prática da EA como uma das grandes preocupações da Educação Escolar, justamente o local privilegiado da enculturação das novas gerações. Compreende-se que esta deve articular os processos simbólicos de apropriação da natureza e de convivência na natureza em seu todo, a partir de um estudo interdisciplinar das relações entre cultura e sustentabilidade das comunidades locais (LEMOS, 2015).

Segundo Leff (2009), a cultura local orienta o uso dos recursos naturais próximos, que, por sua vez, condicionam, até certo grau, as opções de vida de uma determinada comunidade, mas que afetam, também, a humanidade como um todo, pois local e global se encontram de uma forma ou outra.

Assim concebida, a cultura é um recurso social capaz de ser usada destrutiva ou racionalmente, de perder-se ou desenvolver-se. Nesse sentido, em se tratando da questão

Recebido em: $18 / 11 / 2020$

Aceite em: $27 / 07 / 2021$ 
técnico socioambiental, a cultura impõe um olhar que é determinante na interpretação das causas dos graves problemas ambientais que impactam e afetam a vida como um todo na contemporaneidade (LEFF, 2009).

Gadotti (2008) destaca a importância de inserir uma cultura de sustentabilidade no ensino formal. Para o autor, o sistema formal de educação, em geral, é baseado em princípios predatórios, concebido como racionalidade instrumental, reproduzindo valores insustentáveis, como o processo consumista em que todos são jogados para introduzir uma cultura da sustentabilidade nos sistemas educacionais, é necessário reeducar o sistema e compreender que ele faz parte tanto do problema, como também faz parte da solução.

De acordo com concepções de conhecimento escolar que se propõem a ensinar, pode-se educar para formar um pensamento crítico, criativo e prospectivo, aquele que capacita os estudantes a analisar as complexas relações entre os processos naturais, tecnológicos e sociais e para atuar no ambiente com uma perspectiva global, mas diferenciada pelas diversas condições naturais e culturais que os definem (LEFF, 2001). É isso que se propõe indicar nesse estudo.

Diante desse cenário, a realização do estudo inicial com base no que já foi produzido em âmbito específico para o desenvolvimento de uma proposta curricular tornou-se pertinente na medida em que permitiu conhecer pesquisas que discorrem sobre o que está sendo proposto e trabalhado sobre as novas necessidades de conhecimentos, bem como, a relevância da temática ambiental para toda a sociedade, para então analisar suas potencialidades, fragilidades e desafios. Da mesma forma, conhecer essas pesquisas, inicialmente por meio de revisão bibliográfica, torna-se importante passo para conhecer realidades diversas e de como foram compreendidas nas diferentes situações e poder dar um passo adiante.

De forma mais específica, a finalidade deste levantamento bibliográfico foi verificar o que já foi produzido sobre a Sustentabilidade e EA Agrícola no ensino de Química do Ensino Médio. Esse levantamento tem o intuito de conhecer, analisar e discutir os caminhos apontados e, se necessário, indicar novas possibilidades e limites na própria prática da docência em outra realidade. Assim, a questão a ser respondida foi formulada em um pequeno conjunto de perguntas: quais foram as motivações dos diferentes autores, que discutem a temática pesquisada, para a inserção da questão

Recebido em: $18 / 11 / 2020$

Aceite em: 27/07/2021 
ambiental no Ensino de Química? O subtema Sustentabilidade e EA Agrícola foi objeto de preocupação? A Química é compreendida como um tipo de conhecimento que pode impactar o ambiente como o ambiente agrícola?

\section{METODOLOGIA}

No presente estudo, buscou-se, a partir do Estado do Conhecimento, pesquisar as produções oriundas do Mestrado (dissertações) e Doutorado (teses), permitindo assim, saber como vêm sendo trabalhadas as contribuições científicas a respeito da temática, que se encontram disponíveis no período de 2015 a 2019 no Catálogo de Teses e Dissertações da CAPES, considerando a pertinência desse debate atual.

Para a pesquisa, foram utilizados inicialmente, os descritores:

1. Ensino de Química e Educação Ambiental;

2. Ensino de Química e Agrotóxicos;

3. Ensino de Química e Sustentabilidade Ambiental

4. Educação Ambiental Agrícola e Ensino de Química.

A busca com os descritores apresentou um grande número trabalhos, distribuídos em Dissertações e Teses, porém, muitos deles se repetiram, e em alguns casos, afastavam-se do foco desta pesquisa, mesmo quando apresentavam no título ou nas palavras-chaves alguns dos descritores, tendo em vista que, esta pesquisa buscou analisar trabalhos que contemplassem o a Educação Ambiental e os Agrotóxicos no Ensino de Química.

Observou-se, acerca da temática em estudo, relevantes publicações de artigos, resumos expandidos, dissertações e teses nas bases de dados virtuais. Da mesma forma, observou-se que apesar de ser um tema bastante estudado e muito importante para a educação, nos últimos dois anos foram encontrados poucos trabalhos com os descritores mencionados. Na sequência, dialoga-se sobre os principais resultados dos estudos selecionados com a literatura que discorre sobre a temática.

\section{RESULTADOS E DISCUSSÕES}

A pesquisa, definida como Estado de Conhecimento, consiste em registros de trabalhos acadêmicos que permite ter uma ideia da produção científica de uma determinada área, quais foram os temas mais estudados e nos indica possíveis carências

Recebido em: 18/11/2020

Aceite em: $27 / 07 / 2021$ 
de estudo; objetiva, enfim, realizar levantamentos do que se conhece sobre um determinado assunto e o que ainda não foi apontado sobre determinado tema.

No presente estudo, buscamos, a partir do Estado do Conhecimento, limitar a pesquisa sobre as produções oriundas do Mestrado (dissertações) e Doutorado (teses), permitindo, assim, saber como vêm sendo as contribuições científicas a respeito da temática, que se encontram disponíveis nos últimos cinco anos (de 2015 a 2019) no Catálogo de Teses e Dissertações da CAPES. A pesquisa foi norteada utilizando combinações de palavras do tema em estudo, tais como: Ensino de Química e Educação Ambiental; Ensino de Química e Agrotóxicos; Ensino de Química e Sustentabilidade Ambiental; Educação Ambiental Agrícola e Ensino de Química.

A busca com os termos apresentou inúmeros trabalhos, distribuídos em Dissertações e Teses, no período pesquisado entre 2015-2019. Observou-se que apesar de ser um tema bastante estudado e muito importante para a educação, nos últimos dois anos foram encontrados poucos trabalhos com os termos pesquisados. Da mesma forma, é importante destacar que os termos utilizados apareceram em muitos trabalhos e na maioria das buscas, os estudos se repetiam, independentemente dos termos utilizados.

Para tanto, foram incluídos no estudo DM e TD completas da área da educação, publicadas no referido período e que apresentaram no título ou no resumo (palavraschaves) os termos que direcionaram a busca das publicações.

Em seguida, discute-se os principais resultados dos estudos selecionados com a literatura que discorre sobre a temática. Entre os estudos selecionados, observou-se que a EA, apesar de ser uma abordagem explícita dos Parâmetros Curriculares Nacionais (PCNs) e na Lei de Diretrizes e Bases da Educação (LDB) e, mais recentemente, nas Base Nacional Comum Curricular (BNCC), documentos norteadores da Educação (SILVEIRA et al, 2020), ainda é tema pouco trabalhado no Ensino Médio, distanciandose ainda mais das aulas da disciplina de Química. No quadro 1, estão apresentados os trabalhos selecionados, de acordo com cada descritor, bem como, os objetivos e principais resultados observados em cada um.

Quadro 1- Descrição dos trabalhos incluídos no estudo quanto ao título, autor e ano, objetivos e principais resultados por descritor.

Recebido em: $18 / 11 / 2020$

Aceite em: $27 / 07 / 2021$ 


\begin{tabular}{|c|c|c|}
\hline $\begin{array}{l}\text { Título/ } \\
\text { descritores }\end{array}$ & Autor/Documento/Ano & Objetivos e principais resultados \\
\hline \multicolumn{3}{|c|}{ Ensino de Química e Educação Ambiental } \\
\hline $\begin{array}{l}\text { Ambientalização } \\
\text { curricular em } \\
\text { uma perspectiva } \\
\text { de Educação } \\
\text { Ambiental } \\
\text { Freireana }\end{array}$ & $\begin{array}{l}\text { Claudemir Stanqueviski } \\
\text { Dissertação } \\
2019\end{array}$ & $\begin{array}{l}\text { Verificar como o domínio do conceito ambiental } \\
\text { através da educação superior, pode ser verificada } \\
\text { por meio da ambientalização curricular (AC), bem } \\
\text { como, a EA está sendo efetivada na Faculdade } \\
\text { Municipal de Educação e Meio Ambiente (FAMA) } \\
\text { de Clevelândia-PR. No aspecto formativo, a Fama } \\
\text { está educando pessoas para o mundo do trabalho } \\
\text { com vistas a prepará-los para a cidadania, com uma } \\
\text { formação técnica e humana congregadas no sentido } \\
\text { de formar integralmente aos seus acadêmicos. A } \\
\text { AC está contribuindo para criar condições concretas } \\
\text { da construção de uma EA plena para a preservação } \\
\text { ambiental, a partir dos conhecimentos adquiridos } \\
\text { no Ensino Superior. }\end{array}$ \\
\hline $\begin{array}{lr}\text { A inserção } & \text { da } \\
\text { temática } & \\
\text { ambiental } & \text { no } \\
\text { currículo do } & \text { do } \\
\text { Ensino Médio } \\
\text { do estado de São } \\
\text { Paulo }\end{array}$ & $\begin{array}{l}\text { Liliane Samira Becari } \\
\text { Nogueira Domeneghi } \\
\text { Dissertação } \\
2018 \text { are Scienti }\end{array}$ & $\begin{array}{l}\text { Analisar a incorporação de aspectos relacionados à } \\
\text { temática ambiental (temas ambientais, } \\
\text { procedimentos didáticos) no currículo oficial do } \\
\text { ensino médio da rede estadual de São Paulo, bem } \\
\text { como nos respectivos materiais de apoio. Os } \\
\text { autores concluíram que existe a predominância de } \\
\text { elementos da temática ambiental nos materiais da } \\
\text { área de "Ciências da Natureza e suas tecnologias", } \\
\text { embora tenham sido identificados também em } \\
\text { número significativo na área de "Ciências Humanas } \\
\text { e suas tecnologias". Bem como, a predominância } \\
\text { do caráter dicotômico da relação sociedade- } \\
\text { natureza, reforçando uma visão utilitarista do } \\
\text { ambiente. E ainda, foco na adoção de atitudes mais } \\
\text { conscientes em relação às atividades que geram } \\
\text { algum impacto para o ambiente. }\end{array}$ \\
\hline $\begin{array}{l}\text { Os sujeitos do } \\
\text { Ensino Médio e } \\
\text { a cultura da } \\
\text { sustentabilidade }\end{array}$ & $\begin{array}{l}\text { Jaqueline Marcia de } \\
\text { Souza Vieira } \\
\text { Dissertação } 2017\end{array}$ & $\begin{array}{l}\text { Compreender se e de que maneira os docentes e } \\
\text { discentes do Ensino Médio, concebem os aspectos } \\
\text { da cultura da sustentabilidade, no que diz respeito } \\
\text { aos princípios e valores das políticas de EA. } \\
\text { Constatou-se, que a problemática socioambiental, e } \\
\text { indícios de EA e Sustentabilidade, apareceram nas } \\
\text { abordagens da escola. Os docentes e discentes, tem } \\
\text { necessidade de um comprometimento ainda maior } \\
\text { com as causas da EA e da cultura da } \\
\text { sustentabilidade na escola, e consequentemente, na } \\
\text { comunidade local, mesmo que algumas vezes, não } \\
\text { seja efetivado na prática porque não tiveram na sua } \\
\text { formação inicial nem continuada. }\end{array}$ \\
\hline Blog e Educação & Edidácio & Compreender como a ferramenta blog poderia \\
\hline
\end{tabular}

Recebido em: 18/11/2020

Aceite em: 27/07/2021 


\begin{tabular}{|c|c|c|}
\hline $\begin{array}{l}\text { Ambiental: uma } \\
\text { experiência } \\
\text { junto a } \\
\text { estudantes do } \\
\text { Ensino Médio }\end{array}$ & $\begin{array}{l}\text { Chaves } \\
\text { Dissertação } 2016\end{array}$ & $\begin{array}{l}\text { contribuir para repercutir práticas em Educação } \\
\text { Ambiental junto a estudantes do ensino médio. } \\
\text { Nesse sentido, a tecnologia aliada à prática } \\
\text { vivencial e simbólica da EA fundamentada na } \\
\text { ecologia humana, na complexidade e na perspectiva } \\
\text { transdisciplinar mostra-se promissora e deve ser } \\
\text { fomentada, sobretudo na formação de jovens, em } \\
\text { razão de seu dinamismo e sua familiaridade para } \\
\text { esse público. }\end{array}$ \\
\hline $\begin{array}{l}\text { Educação } \\
\text { Ambiental em } \\
\text { escola de Ensino } \\
\text { Médio } \\
\text { localizada no } \\
\text { campo do } \\
\text { município de } \\
\text { Rio Branco do } \\
\text { Sul }\end{array}$ & $\begin{array}{l}\text { Maria Helena Costa } \\
\text { Dissertação } 2016\end{array}$ & $\begin{array}{l}\text { Analisar a EA no contexto da Educação do Campo; } \\
\text { conhecer o perfil dos professores que atuam no } \\
\text { ensino médio da escola; analisar a prática } \\
\text { pedagógica dos professores na perspectiva da EA } \\
\text { em escola localizada no campo; examinar a visão } \\
\text { dos alunos de } 3^{\circ} \text { ano do ensino médio sobre a } \\
\text { prática pedagógica em EA; e examinar a concepção } \\
\text { da EA no Projeto Político Pedagógico (PPP) desta } \\
\text { escola. As práticas pedagógicas dos professores na } \\
\text { EA são realizadas de forma isolada e pontuais, não } \\
\text { expressando a realidade do sujeito que vive no } \\
\text { campo; os professores necessitam cursos e } \\
\text { capacitações específicos na área, demonstrando que } \\
\text { sem formação adequada essas práticas pedagógicas } \\
\text { podem se tornar insignificantes aos alunos. Para os } \\
\text { alunos a EA está presente na escola, porém alguns } \\
\text { professores trazem a temática para dentro da sala de } \\
\text { aula. O PPP menciona a EA, mas não possui a } \\
\text { abordagem condizente com a realidade da escola. }\end{array}$ \\
\hline $\begin{array}{l}\text { Educação } \\
\text { Ambiental: uma } \\
\text { política pública } \\
\text { inacabada }\end{array}$ & $\begin{array}{l}\text { Galsione Cruvinel da } \\
\text { Silva Avelar } \\
\text { Dissertação } \\
2016\end{array}$ & $\begin{array}{l}\text { Investigar sobre as ações educativas realizadas em } \\
\text { uma escola pública municipal da cidade de } \\
\text { Uberaba-MG, em relação à EA. A temática deveria } \\
\text { ser um instrumento muito eficaz para se conseguir } \\
\text { criar e aplicar formas sustentáveis de interação } \\
\text { sociedade-natureza, para que cada indivíduo mude } \\
\text { de hábitos e assume novas atitudes que levem à } \\
\text { diminuição da degradação ambiental, promova a } \\
\text { melhoria da qualidade de vida e reduza a pressão } \\
\text { sobre os recursos ambientais. }\end{array}$ \\
\hline \multicolumn{3}{|c|}{ Ensino de Química e Sustentabilidade Ambiental } \\
\hline $\begin{array}{l}\text { Educação } \\
\text { Ambiental e a } \\
\text { construção da } \\
\text { Sustentabilidade } \\
\text { na região de } \\
\text { Várzea de } \\
\text { Santarém (PA) - } \\
\text { Brasil }\end{array}$ & $\begin{array}{l}\text { Antônia do Socorro } \\
\text { Pena da Gama } \\
\text { Tese } \\
2016\end{array}$ & $\begin{array}{l}\text { Explicar a importância do processo de EA na } \\
\text { intervenção dos atores locais para a sustentabilidade } \\
\text { das comunidades de Várzea do município } \\
\text { supramencionado. A pesquisa relata a importância } \\
\text { deste processo educativo junto às comunidades e à } \\
\text { Colônia de Pescadores na implementação de } \\
\text { estratégias de manejo sustentável dos recursos } \\
\text { naturais, e de políticas públicas socioambientais } \\
\text { que resultaram desta intervenção. Os resultados }\end{array}$ \\
\hline
\end{tabular}

Recebido em: 18/11/2020

Aceite em: 27/07/2021 


\begin{tabular}{|c|c|c|}
\hline & & $\begin{array}{l}\text { indicam ainda que, durante o processo, a proposta } \\
\text { educacional de Paulo Freire foi uma das grandes } \\
\text { inspirações dos atores envolvidos proporcionando } \\
\text { uma interpretação crítica das respostas alcançadas. }\end{array}$ \\
\hline $\begin{array}{l}\text { Limites e } \\
\text { possibilidades } \\
\text { na transição para } \\
\text { espaços } \\
\text { Educadores } \\
\text { Sustentáveis em } \\
\text { escolas } \\
\text { municipais de } \\
\text { São João Batista } \\
\text { - SC }\end{array}$ & $\begin{array}{l}\text { Dissertação } \\
2015\end{array}$ & $\begin{array}{l}\text { Analisar como duas escolas de Educação Básica do } \\
\text { município de São João Batista - SC, traduzem e } \\
\text { contextualizam em suas práticas, os fundamentos e } \\
\text { princípios das Diretrizes Curriculares Nacionais } \\
\text { para a Educação Ambiental - DCNEA, e do } \\
\text { Programa Nacional Escolas Sustentáveis - PNES, } \\
\text { visando a sua transição para Espaços Educadores } \\
\text { Sustentáveis (EES), entendidos como aqueles que } \\
\text { têm a intencionalidade pedagógica de se constituir } \\
\text { em referências concretas de sustentabilidade } \\
\text { socioambiental As escolas possuem limitações } \\
\text { quanto ao processo de transição para um EES, mas } \\
\text { que também possuem possibilidades para que o } \\
\text { mesmo aconteça. }\end{array}$ \\
\hline $\begin{array}{l}\text { Práticas } \\
\text { Pedagógicas de } \\
\text { Educação } \\
\text { Ambiental em } \\
\text { escolas } \\
\text { municipais de } \\
\text { Manaus }\end{array}$ & $\begin{array}{l}\text { Ana Rafaela Gonçalves } \\
\text { de Lemos } \\
\text { Dissertação } \\
2015\end{array}$ & $\begin{array}{l}\text { Analisar as práticas pedagógicas de EA na } \\
\text { execução da Agenda Ambiental Escolar em duas } \\
\text { escolas municipais de Manaus. As práticas } \\
\text { pedagógicas mostraram-se incipientes, } \\
\text { considerando de forma "simplista" com que são } \\
\text { abordadas a complexidade ambiental e suas } \\
\text { implicações na sociedade e no contexto escolar o } \\
\text { que remete a uma prática conservadora da EA. }\end{array}$ \\
\hline \multicolumn{3}{|c|}{ Educação Ambiental Agrícola e Ensino de Química } \\
\hline $\begin{array}{l}\text { Educação lns } \\
\text { Ambiental nos } \\
\text { colégios dos } \\
\text { assentamentos } \\
\text { organizados no } \\
\text { MST: } \\
\text { Tendências } \\
\text { Conservadora e } \\
\text { Crítica }\end{array}$ & $\begin{array}{l}\text { Marlene Aparecida } \\
\text { Comin de Araújo } \\
\text { Tese } \\
2019\end{array}$ & $\begin{array}{l}\text { Investigar como se constitui a EA no enfoque das } \\
\text { correntes/macrotendências conservadora e crítica } \\
\text { nos projetos escolares dos colégios estaduais do } \\
\text { campo localizados em assentamentos rurais do } \\
\text { Paraná. Há uma heterogeneidade de ideias nos } \\
\text { projetos escolares, evidenciando a presença de } \\
\text { aspectos da concepção conservadora e crítica. } \\
\text { Refletindo também nos atuais debates teórico- } \\
\text { metodológicos no campo da EA, marcado pela } \\
\text { disputa dos PPPs na produção de conhecimentos, } \\
\text { nas práticas, nas políticas e na atuação } \\
\text { socioambiental de gestores e educadores. }\end{array}$ \\
\hline $\begin{array}{l}\text { A Dimensão } \\
\text { Política da } \\
\text { Educação } \\
\text { Ambiental: } \\
\text { experiências } \\
\text { significativas do } \\
\text { professor na } \\
\text { educação básica. }\end{array}$ & $\begin{array}{l}\text { Tatiana Novaes de } \\
\text { Oliveira } \\
\text { Dissertação } \\
2018\end{array}$ & $\begin{array}{l}\text { Mobilizar sentidos sobre a relação entre as } \\
\text { experiências de vida de oito professores da } \\
\text { educação básica e a dimensão política da EA, de } \\
\text { forma a compreender as possibilidades que as } \\
\text { diferentes experiências de vida oferecem para a } \\
\text { sensibilização dos professores, para o trabalho com } \\
\text { a temática ambiental. Identificou-se as motivações } \\
\text { para o trabalho, bem como os conteúdos, recursos e } \\
\text { procedimentos didáticos que os professores }\end{array}$ \\
\hline
\end{tabular}

Recebido em: 18/11/2020

Aceite em: 27/07/2021 


\begin{tabular}{|l|l|l|}
\hline & $\begin{array}{l}\text { recorrem ao tentar incluir a temática ambiental em } \\
\text { suas aulas, como também, possibilidades e e } \\
\text { limitações para esse trabalho. }\end{array}$ \\
\hline
\end{tabular}

Fonte: Autora (2020)

De acordo com Lemos (2015) há uma grande preocupação de todos os setores da sociedade sobre os efeitos da degradação ambiental no ambiente. Essas questões se colocam como um grande desafio: pensar em ações educativas para formar indivíduos capazes de refletir sua relação com a sociedade e o ambiente, para garantir qualidade de vida e condições de sobrevivência na Terra para as atuais e futuras gerações. Nesse contexto, a Educação Ambiental com sua dimensão abrangente, é forte aliada para reorientar a educação em direção à sustentabilidade.

Ante o crescente e acelerado processo de degradação ambiental, assim como de seus efeitos nos desequilíbrios ecológicos e das bases de sustentabilidade ecológica do planeta, pouco a pouco se vem reconhecendo o papel imprescindível da cultura na sustentabilidade ecológica - das diversas culturas na coevolução da natureza e de seu entrelaçamento com a trama ecológica do planeta (LEFF, 2009, p. 272).

Partilhando dessa concepção, Gama (2016) observou que um dos pontos fortes em seu estudo foi que a EA passou a ser vista pelos atores locais como um processo provido de muitas conquistas, visto que o conhecimento dos cidadãos há de ser o ponto de partida para uma sociedade inteira e significantemente sustentável. No estudo em questão, a proposta educacional de Paulo Freire nesta experiência se adaptou aos novos conceitos, a uma realidade amazônica com suas peculiaridades, a um novo ciclo de atores de instituições de pesquisa e organizações não governamentais que integraram a ciência, qualificando sua intervenção propositiva na implementação de políticas públicas.

Stanqueviski (2019) também buscou na perspectiva da Educação Ambiental Freireana verificar como o domínio do conceito ambiental pode ser verificado por meio da ambientalização curricular (AC) na Faculdade Municipal de Educação e Meio Ambiente (FAMA) de Clevelândia-PR no ensino superior, com vistas à formação de profissionais conscientes que se reconhecem como sujeitos ambientais. Nessa direção, o autor observou que no aspecto formativo, a instituição educa pessoas para o mundo do

Recebido em: $18 / 11 / 2020$

Aceite em: 27/07/2021 
trabalho com vistas a prepará-los para a cidadania, com uma formação técnica e humana congregadas integralmente aos seus acadêmicos.

O conhecimento construído reforça a desconexão do ser humano de sua realidade ambiental e do contato com a natureza e encontra-se em dificuldade quanto a sua definição e efetiva aplicação. A ideia de AC está contribuindo muito para criar condições concretas da construção de uma EA na sua plenitude para a formação de sujeitos responsáveis pela preservação ambiental, a partir dos conhecimentos adquiridos no Ensino Superior.

Já Lemos (2015) entende que a transversalidade da EA é a base fundamental de toda a sua abordagem, principalmente no âmbito do Ensino Formal de Educação. Nesse sentido, é importante que todos os educadores, seja qual forem suas áreas de atuação, tenham conhecimento sobre a forma como EA está inserida nas disciplinas do currículo. Especificamente no contexto da transversalidade da EA, conforme Lemos (2015), a importância da associação com o trabalho interdisciplinar, uma vez que ambas apontam a complexidade do real e a necessidade de se considerar a teia de relações entre os seus diferentes e contraditórios aspectos.

Em seu estudo de abordagem qualitativa em duas escolas, e posterior análise de conteúdo, Mota (2015) observou que os resultados apontaram para a existência de limitações no que se refere ao processo de transição para um EES, mas que também há possibilidades para que o mesmo aconteça.

Como principais limitações destacaram-se o desconhecimento das intencionalidades e objetivos do PNES, do PDDE Escolas Sustentáveis e das Políticas públicas em Educação Ambiental; a falta de formações continuadas em EA; a ausência de diálogos entre os sujeitos da comunidade escolar; bem como a fragilidade do PPP.

Como possibilidades, apontam-se os indícios em direcionar as práticas de ensino à ressignificação dos valores ambientais dos alunos; o reconhecimento por parte dos docentes e gestores acerca da importância de se trabalhar a temática ambiental envolvendo a comunidade escolar e local; a ocorrência de um diálogo entre os saberes populares e os científicos; e a aposta nas formações em EA como fonte de construção e reconstrução de concepções e percepções no que tange às questões ambientais e sustentáveis.

Recebido em: $18 / 11 / 2020$

Aceite em: $27 / 07 / 2021$ 
A esse respeito, Chaves (2016) recorrendo a uma abordagem qualitativa, realizada com rodas de conversa e oficinas de sensibilização, com os sujeitos refletindo sobre o Eu, o Outro e o planeta Terra, observaram a repercussão de uma EA fundada na complexidade e ecologia humana. A compreensão dos estudantes acerca das dimensões tratadas mostrou que eles conseguiram ultrapassar um entendimento linear e simplista sobre o meio ambiente assim como, transpuseram para a ferramenta blog as produções baseadas nas discussões temáticas, conseguindo os retornos em forma de comentários.

A ferramenta digital demonstrou seu potencial pedagógico para a EA, articulada ao processo vivencial e simbólico desenvolvido presencialmente nas oficinas. Juntos, blog e oficinas vivenciais contribuíram não só para a formação dos estudantes que participaram da pesquisa, motivando-os, sensibilizando-os, despertando interesse, criatividade e envolvimento cada vez maior com a temática ambiental, como também, para a formação e reflexão de outros, a partir do compartilhamento de conhecimentos, experiências, reflexões e da possibilidade do diálogo com outros.

Nesse sentido, Lemos (2015) explica a necessidade em não se reduzir a prática da EA a um discurso voltado apenas a um fim que seria a conservação do meio ambiente, encerrando a complexidade das questões socioambientais, sem considerar que essa problemática gera impacto em todas as dimensões da vida do educando e que se efeitos também estão presentes no âmbito da escola. Desse modo, a educação para a sustentabilidade implica em configurações centradas em conteúdos e vivências, em direção a novas práticas de aprendizagem, as quais devem considerar as relações de produção de conhecimento e os processos de circulação, transmissão e disseminação de saber ambiental.

Isto traz "a necessidade de serem incorporados os valores ambientais e os novos paradigmas do conhecimento" (LEFF, 1999, p.127), na formação de novos sujeitos para uma prática da EA sob o viés da sustentabilidade. Entende-se que a prática da EA não se resume apenas na transmissão de informações a respeito dos processos ecológicos, na perspectiva do "conhecer para preservar", esse tipo de abordagem é absolutamente insuficiente para promoção de uma educação onde que se pretende uma crítica e transformadora da realidade. Por outro lado, é preciso reconhecer que a efetivação teórico/prático da EA não é propriamente a ausência de conhecimentos ecossistêmicos, a desinformação a respeito dos aspectos ecológicos.

Recebido em: $18 / 11 / 2020$

Aceite em: 27/07/2021 
Esse aspecto foi observado também no estudo de Chaves (2016) em que a Educação Ambiental possibilitou aos sujeitos compreenderem que as três dimensões (social, ambiental e econômica), dado o caráter de inseparabilidades entre elas, foram abrindo visões em retrospectiva e em perspectiva que apontaram questionamentos ligados à temática ambiente que podem figurar simultaneamente em qualquer uma delas. Descobrirem-se como parte do ambiente foi o primeiro passo que os levou a perceberem que a vida se constitui e mantém estreita ligação com esse mesmo ambiente. Essa constatação despertou nos sujeitos tanto a dimensão objetiva quanto a subjetiva para dar resposta aos questionamentos levantados, evidenciando que o pensar e o sentir não são separados.

Em outras palavras, torna-se necessário ter como meta para toda formação a emancipação humana e a transformação social. A pedagogia freireana oferece subsídios concretos para pensar o sentido de aprender em processo a realidade ambiental. Para isso é necessário entender as concepções de mundo, homem e educação (STANQUEVISKI, 2019).

Nessa perspectiva, ao analisar a EA nos colégios dos assentamentos organizados no MST, Araújo (2019) observou que, mesmo se tratando de escolas do campo, existem limites no tratamento da temática pela equipe gestora e multidisciplinar; os projetos não abordam os problemas inerentes à realidade do campo; as disciplinas que apresentam maior flexibilidade no tratamento da EA são Ciências, Geografia e Biologia; os PPPs e, em decorrência, em EA não fazem referência à Política de Educação Ambiental (PNEA).

Diante disso, evidencia-se o distanciamento entre a sustentabilidade e a EA agrícola. Da mesma forma, não são observadas atividades relacionadas ao ensino de química enquanto geradora de conhecimento ambiental e seus impactos no ambiente em que os alunos estão inseridos, tal como, o estudado.

Esse fato pode estar relacionado ao observado por Oliveira (2018), onde o autor enuncia que os professores realizam diversas tentativas de incluir a temática ambiental em suas disciplinas por meio de relações com os conteúdos curriculares específicos de cada disciplina. Nessa tentativa cada professor se apoia em recursos e procedimentos didáticos variados, como o uso dos recursos audiovisuais, filmes, documentários, fotos e apresentação de slides, entre outros.

Recebido em: $18 / 11 / 2020$

Aceite em: 27/07/2021 
No entanto, os professores ainda vivenciam a EA de maneira simplista, ao perceberem que a construção de uma horta escolar é vista como uma iniciativa que poderia ser melhor explorada para o trabalho com a temática ambiental. A esse respeito, é preciso chamar atenção para a complexidade da EA a partir do conceito do "todo", precisando ser vista em sua globalidade, em todas as ações cotidianas, não limitando-se à construção de espaços reduzidos, que de certa forma, não permitem a visualização da conectividade dos sistemas e das disciplinas.

Avelar (2016) corrobora com a discussão ao explicar que a EA na escola deveria ser hoje um instrumento muito eficaz para se conseguir criar e aplicar formas sustentáveis de interação sociedade-natureza. Este é o caminho, para cada indivíduo mudar de hábitos e assumir novas atitudes que levem à diminuição da degradação ambiental, promova a melhora da qualidade de vida, reduza a pressão sobre os recursos ambientais, atuando ativa e efetivamente no meio em que está inserido, de forma a contribuir para a preservação planetária.

Mesmo que esse processo seja, na maioria das vezes, implementado lentamente nas escolas e, mais ainda, pelas disciplinas que fogem da área das Ciências da Natureza, é preciso que a escola subsidie ações que vêm ao encontro da política da EA. Vieira (2017) observou essas questões em seu estudo e chamou atenção para o fato de que os docentes e discentes devem ter a necessidade de um comprometimento ainda maior com as causas da EA e da cultura da sustentabilidade na escola como também comunidade local.

No entanto, na maioria das vezes, os docentes não sabem como efetivá-las na prática (interligar currículo, gestão democrática, espaço físico e relação com a comunidade) porque essas estratégias e metodologias não foram proporcionadas e trabalhadas em sua formação inicial e continuada (ALARCON; BOELTER, 2019).

Diante dessa realidade desvelada por Vieira (2017), enfatiza-se a importância da oferta constante de formação continuada em EA para a equipe escolar, com o propósito de abrir horizontes e direcionar a práxis pedagógica aos sujeitos da EA e a comunidade local como um todo, para que se estabeleçam, de maneira contínua e unânime, a cultura da sustentabilidade proposta pelas Políticas Nacional e Estadual de Educação Ambiental.

Recebido em: $18 / 11 / 2020$

Aceite em: 27/07/2021 
Pertinente a isso, Domeneghi (2018) analisou a incorporação de aspectos relacionados à temática ambiental (temas ambientais, procedimentos didáticos) no currículo oficial do Ensino Médio da Rede Estadual de São Paulo, bem como nos respectivos materiais de apoio (caderno do aluno e caderno do professor), de todas as disciplinas e áreas do conhecimento, em suas pesquisas, observou a inserção da temática ambiental no currículo e em seus materiais de apoio de forma incoerente e contraditória com o estabelecido nas DCNEA e com o referencial teórico adotado na sua pesquisa, revelando limitado potencial transformador da relação estabelecida entre sociedadenatureza, uma vez que não problematiza o consumo, o modo de vida e de produção na sociedade capitalista.

Além disso, Domeneghi (2018) destacou elementos como, a ênfase no caráter danoso para o ambiente proveniente das ações antrópicas, a adoção de atitudes individuais de redução de impactos ambientais sem problematizar o consumo e o modo de produção, a predominância de procedimentos didáticos que pouco colaboram para o debate, a discussão e reflexão acerca da problemática ambiental, atrelados à dicotomia entre ensino e aprendizagem.

Da mesma forma, a ênfase no desenvolvimento de habilidades e competências expressos no currículo revelam uma possível influência da visão neoliberal de educação na elaboração destes documentos, reforçando uma perspectiva acrítica deste currículo, que pode acabar por silenciar algumas vozes, experiências, histórias e trajetórias pelas quais os alunos são constituídos e dão sentido ao mundo que os cerca (DOMENEGHI, 2018).

Nesse sentido, reitera-se a importância da EA ser trabalhada nas escolas a partir do seu próprio bojo, ou seja, dentro do escopo proposto pela Política que a instituiu, as DCNs e, mais recentemente, a BNCC. É preciso que as escolas, professores, alunos, comunidades do entorno falem e vivenciem o mesmo discurso, e que este se efetive na prática e na realidade dos envolvidos, tal como destacado pelos autores dos estudos analisados.

\section{CONCLUSÃO}

O Estado do Conhecimento nessa abordagem, possibilitou entender que os diferentes estudos analisados trouxeram diversas motivações dos seus autores, porém, essa diversidade esteve alicerçada em parte no ensino da química e sua relação com a

Recebido em: $18 / 11 / 2020$

Aceite em: $27 / 07 / 2021$ 
EA, no sentido de se conhecer como está sendo trabalhada essa questão nessa disciplina, além, da pertinência e urgência da formação continuada dos docentes de forma a subsidiar estratégias de implementação dos conteúdos nas escolas.

Da mesma forma, observou-se que o subtema Sustentabilidade e EA Agrícola foi objeto de pouca preocupação e difusão do conhecimento. Os trabalhos que emergiram da busca, para o descritor afim, mesmo quando analisaram a realidade de escolas em assentamentos ou de educação do campo, encontraram dissonâncias entre a proposta da EA e a Sustentabilidade com as práticas agrícolas, revelando assim, que apesar de todo processo de implantação da temática no cenário educacional, os projetos não abordam os problemas inerentes à realidade do campo; as disciplinas que apresentam maior flexibilidade no tratamento da EA são Ciências, Geografia e Biologia, não ocorrendo de forma inter, multi ou transdisciplinar.

Para finalizar, cumpre destacar nos trabalhos analisados, que as práticas pedagógicas da EA ainda têm ocorrido de forma "incipiente", pouco efetivas no enfrentamento da questão socioambiental no contexto escolar, principalmente como atividade curricular continuada.

Diante disso, reitera-se a pertinência do projeto de doutorado realizado com alunos do Ensino Médio no Estado do Paraná, partindo-se de um plano de atividades que os envolvem no campo social em que estão inseridos, e consequentemente, discutindo-se a EA e a sustentabilidade nas escolas, uma vez que ambas demandam orientações e conteúdo; novas práticas pedagógicas, nas quais se moldam as relações de produção de conhecimento e os processos de circulação, transmissão e disseminação de saber ambiental.

Pensar em práticas pedagógicas de EA requer um esforço que vai além de uma prática que tem um interesse voltado apenas em cumprir o que preconiza os PCN sobre os "temas transversais". Isso se traduz, em muitas vezes, buscar além das práticas pedagógicas esporádicas ou em sugestões de livros didáticos, como atividades vazias e desarticuladas da realidade socioambiental dos educandos, priorizando uma fundamentação teórica/ metodológica estruturada sobre o viés da sustentabilidade, com ações que considerem a cultura local como ponto de partida para a compreensão da relação homem e natureza. 


\section{REFERÊNCIAS}

ALARCON, A, M.Y.; BOELTER, R.A. O meio ambiente segundo alunos do $5^{\circ}$ ano do ensino fundamental. Revista insignare Scientia-RIS, v. 2, n. 2. Mai./Ago. 2019.

ARAÚJO, M. A.C. de. Educação ambiental nos colégios dos assentamentos organizados no MST: tendências conservadoras e crítica. Tese (Doutorado) Universidade Tuiuti do Paraná, Curitiba, 2019.

AVELAR, G. C. da S. Educação Ambiental: uma política pública inacabada. Dissertação de Mestrado. Universidade de Uberaba - UNIUBE. Uberaba, 2016.

BOFF, L. O despertar da Águia. Petrópolis: Vozes, 1997.

1999.

Saber cuidar: ética do humano, compaixão pela terra. Petrópolis: Vozes,

CHAVES, E.A. Blog e educação ambiental: uma experiência junto a estudantes do Ensino Médio. Dissertação (Mestrado). Programa de Pós-Graduação em Educação da Universidade de Brasília, Brasília, 2016.

CORRÊA, M.L.; MEGGIOLARO, G. P.; REIS, A.Q. M. Abordagem do conteúdo de frações a partir do programa Nacional do Livro Didático. Revista de Ensino de Ciências e Matemática, v. 10, n. 6, p. 21-38, 2019.

COSTA, M.H. Educação Ambiental em escola de Ensino Médio localizada no campo do município de Rio Branco do Sul. Dissertação (Mestrado em Educação). Programa de Pós-Graduação em Educação da Universidade Tuiuti do Paraná, Curitiba, 2016.

DOMENEGHI, L.S.M. A inserção da temática ambiental no currículo do Ensino Médio do estado de São Paulo. Dissertação (Mestrado em Educação). Programa de Pós-Graduação em Educação, do Instituto de Biociências da Universidade Estadual Paulista “Júlio de Mesquita Filho" - UNESP/ Campus de Rio Claro. Rio Claro, 2018.

GADOTTI, M. Educar para a sustentabilidade. In: Inclusão Social, Brasília, v. 3, n. 1, p. $75-78$, out. 2007/mar. 2008.

GAMA, A. S. P. da. Educação ambiental e a construção da sustentabilidade na região de Várzea de Santarém (PA) - Brasil. Tese (doutorado). Universidade Estadual de Campinas, Faculdade de Educação. Campinas, SP, 2016.

LEFF, E. Complexidade, racionalidade ambiental e diálogo de saberes. In: Educação \& realidade. - Porto Alegre. - V.34 (3), Set.-Dez., 2009, pp. 17-24.

Epistemologia ambiental. 2. ed. São Paulo: Cortez, 2002.

Educação ambiental e desenvolvimento sustentável. In REIGOTA,

Recebido em: $18 / 11 / 2020$

Aceite em: $27 / 07 / 2021$ 
M.(org.). Verde cotidiano: o meio ambiente em discussão. Rio de Janeiro: DP\&A, 1999 (p.111-129).

LEMOS, A.R.G. Práticas pedagógicas de Educação Ambiental em escolas municipais de Manaus. Dissertação (Mestrado) Programa de Pós-Graduação em Educação. Universidade Federal do Amazonas. Manaus, 2015.

MALDANER, O.A. et al. Currículo contextualizado na área de ciências da natureza e suas tecnologias: a situação de estudo. In: ZANON, L.B. e MALDANER, O.A. (Orgs). Fundamentos e propostas de ensino de química para a educação básica no Brasil. (Coleção Educação em Química). Ijuí: Ed. UNIJUÍ, 2007, p.109-138.

MINAYO, M.C.S. (Org.). Pesquisa Social: teoria, método e criatividade. 29 ed. Petrópolis, RJ: Vozes, 2010.

MOTA, J.C. Limites e possibilidades na transição de escolas para espaços educadores sustentáveis no município de São João Batista - SC. Dissertação (Mestrado). Programa de Pós-Graduação em Educação - PPGE, UNIVALIUniversidade do Vale do Itajaí-SC, 2015.

OLIVEIRA, T.N.de. A Dimensão Política da Educação Ambiental: experiências significativas do professor na educação básica. Dissertação (Mestrado) Universidade Estadual Paulista (UNESP), Instituto de Biociências Rio Claro, 2018.

PAIVA, M.R.F. et al. Metodologias ativas de ensino-aprendizagem: revisão integrativa. Sanare, Sobral, v.15, n.02, p.145-153, Jun./Dez. - 2016.

SANTOS, W.L.P.; AULER, D. (Org.) CTS e educação científica: desafios, tendências e resultados de pesquisas. Brasília: Editora Universidade de Brasília, 2011.

SANTOS, W.L.P; SCHNETZLER, R.P. Educação em Química: Compromisso com a cidadania. 4. ed. rev. atual. Ijuí: Ed. Unijuí, 2015.

STANQUEVISKI, C. Ambientalização curricular em uma perspectiva de educação ambiental freireana. Dissertação (Mestrado em Educação) - Universidade Comunitária da Região de Chapecó, 2019.

SILVEIRA, M.; SOARES, J.; COSTA, M.; PESSANO, E. Investigando a abordagem da Educação Ambiental em uma escola no município de Uruguaiana/RS. Revista Insignare Scientia - RIS, v. 3, n. 5, p. 25-44, 18 dez. 2020.

VIEIRA, J.M.S. Os sujeitos do ensino médio e a cultura da sustentabilidade. Curso de Dissertação (Mestrado Acadêmico em Educação). Programa de Pós-Graduação em Educação- PPGE. Universidade do Vale do Itajaí- UNIVALI, 2017.

VIGOTSKI, L. S. A construção do pensamento e da linguagem. 2.ed. São Paulo: WMF Martins Fontes, 2009. 